\title{
EL CINE COMO INSTRUMENTO DE REINTERPRETACIÓN HISTÓRICA EN PERIODOS DE TRANSICIÓN DEMOCRÁTICA
}

\section{CINEMA AS AN INSTRUMENT OF HISTORICAL REINTERPRETATION IN PERIODS OF DEMOCRATIC TRANSITIONS}

\author{
Jaime Porras Ferreyra*
}

\section{RESUMEN}

Este artículo aborda el uso del cine como instrumento de difusión de ideas en un contexto específico, en este caso sobre su papel dentro de las transiciones a la democracia para poder presentar a la ciudadanía una reinterpretación histórica y así ir a contracorriente de la historia oficial de los regímenes autoritarios. Para ello se analiza concretamente el carácter político de las obras de diversos cineastas en España y México, en plena época de transformación político-institucional. Factores como la desmitificación de algunos eventos históricos, la presencia en la pantalla de actores políticos tradicionalmente ignorados y la crítica a ciertos valores propios del autoritarismo sirven de ejemplo de la capacidad del séptimo arte como espacio de acción política.

PALABRAS CLAVE: ESPAÑA * MÉXICO * HISTORIA POLÍTICA * CINE * DEMOCRATIZACIÓN

* ACTORES POLÍTICOS

ABSTRACT

The following article studies the use of cinema as an instrument of ideas in a specific context, in this case, its role in democratic transitions with the objective to present to the citizens a historical reinterpretation in order to dispute the current views of the official history of the authoritarian regimes. To demonstrate this, the political character of motion pictures from Spain and Mexico during the political-institutional transformation will be analyzed. Factors like the demystification of some historical events, the screen presence of political actors traditionally ignored and the critique of certain values linked to authoritarianism become examples of the capacity of the seventh art as a space of political action.

KEYWORDS: SPAIN * MEXICO * POLITICAL HISTORY * CINEMA * DEMOCRATIZATION * POLITICAL ACTORS 
A pesar de varias décadas alejado de la ciencia política, el cine ha despertado en los últimos años un mayor interés por parte de distintos politólogos. Luego de que varias disciplinas tales como los estudios cinematográficos, los denominados cultural studies y la antropología han efectuado análisis "políticos" de distintas obras fílmicas, los estudiosos de la política comienzan a constatar la importancia del cine como objeto político por tratarse de un fenómeno social y de un instrumento de difusión masiva de mensajes de diversa índole. De esta manera, temas como la relación entre la cámara y el nacimiento, desarrollo y consolidación de diversos regímenes autoritarios, el papel de los cineastas dentro de las luchas sindicales y de la crítica efectuada por parte de varios directores a diversas problemáticas sociales - pensemos por ejemplo en la cuestión del medio ambiente, los derechos indígenas, la condición de la mujer $y$ la diversidad sexual - dan cuenta, por una parte, de la diversidad discursiva presente en la pantalla grande y, por la otra, del creciente interés del cine como objeto político.

Uno de los eventos que han producido un vasto interés en las últimas décadas por parte de muchos de los estudiosos de la ciencia política es el caso de las transiciones y consolidaciones democráticas. En efecto, desde el inicio de la denominada Tercera Ola de Democratización (Huntington, 1991), diversos países circularon de un régimen político autoritario a otro de corte democrático en distintas regiones del orbe. Para el estudio de dichos cambios de régimen han sido utilizados varios enfoques tales como el peso de la economía, el papel de las élites negociadoras, el contexto internacional y la cultura política (Badie, 1988) (Gazibo y Jenson, 2004). El propósito fundamental de nuestra investigación es subrayar el papel del cine como instrumento de difusión de ideas políticas en esta época de transformación político-institucional, señalando que un cambio de régimen es un proceso complejo que involucra a distintos actores $y$ escenarios $y$ donde las expresiones artísticas -en este caso concreto, el séptimo arte- pueden representar un canal efectivo de difusión de diversos mensajes políticos. Dentro de todas las formas posibles de participación a través de la cámara, centraremos nuestra atención en el papel del cine, tal y como lo comentan distintos autores, en uno de los puntos ignorados frecuentemente por la denominada Transitología: la importancia del pasado en los debates sobre las transiciones políticas. Para ello, analizaremos en concreto los casos de España y México. La democratización de España es vista tradicionalmente como el caso de transición ejemplar, sin embargo, las cuestiones históricas fueron y siguen representando un punto polémico en todos los sectores sociales. En el caso de México, hablamos de una transición más reciente pero donde de igual manera el peso del pasado, luego de años de censura $y$ de la difusión sistemática de una "historia oficial", se ha convertido en un aspecto de vital importancia dentro del proceso de democratización. De esta manera, profundizaremos sobre el papel de los cineastas en estos dos países como creadores de obras que tocan directamente las cuestiones históricas en periodos de constantes cambios políticos y sociales.

\section{EL ESTUDIO DE LOS CAMBIOS DE RÉGIMEN}

El estudio de las formas y mecanismos en que un país circula de un régimen a otro ha acaparado la atención de diversos politólogos desde hace varias décadas. A través del tiempo, distintas perspectivas han sido utilizadas para explicar con detalle los cambios de régimen. En un primer momento, algunos autores se concentraban en el desempeño de las instituciones políticas como único factor explicativo. Durante los años sesenta y setenta, las tesis estructurales basadas en la instauración de un conjunto de prerrequisitos tales como el desarrollo económico y cultural, cobraron una gran importancia dentro de la disciplina, principalmente a través de los trabajos de Seymour Martin Lipset, Gabriel Almond, Sydney Verba, J.R. Pennock, E.S. Griffith y J. Plamenatz (Badie, 1988). Existieron poco después algunas tesis que ligaban directamente la acción de una clase social específica con la difusión y el desarrollo de la democracia - Barrington Moore y la burguesía; Rueschemeyer, Stephens y Stephens y la clase 
trabajadora- (Gazibo y Jenson, 2004). A finales de los años setenta, $y$ debido a las transiciones experimentadas en el Mediterráneo por Grecia, Portugal y España, algunos autores comenzaron a privilegiar una perspectiva basada fundamentalmente en las decisiones de los actores políticos tradicionales. De esta manera, una transición era entendida como el resultado de pactos, negociaciones y alianzas entre sectores de la oposición y miembros del régimen autoritario simpatizantes de llevar a cabo toda una serie de reformas. Así, diversos trabajos de parte de algunos politólogos dieron lugar a la denominada Transitología (O’Donnell y Schmitter, 1986) (Karl y Schmitter, 1991) (Linz y Stepan, 1996). Para estos autores, arribar a una democracia no es el resultado de un proceso de transformación en lo económico o en lo cultural sino el fruto de las relaciones entre las élites políticas, que realizaban reuniones y acuerdos con base a cálculos estratégicos. Es por ello que dichos autores se inclinaron más por una definición mucho más electoral de la democracia, fundamentada en su capacidad para elegir gobernantes por medio de prácticas bien definidas.

Con el paso de los años, otros estudiosos han continuado en el análisis de diversos aspectos ligados a las transiciones democráticas. Citemos por ejemplo, las reflexiones en torno a la importancia del Estado de derecho en las nuevas democracias, a la imputabilidad de las autoridades gubernamentales y a la distribución del poder (O'Donnell, 1992) (Valenzuela, 1993). De igual manera se han dejado escuchar algunas críticas en torno a la Transitología, acusándola de concentrar demasiado su atención en las élites y en no contar con las herramientas necesarias para explicar formas de régimen difíciles de catalogar (Carothers, 2002). En este orden de ideas, otros autores más añaden al papel de las élites la participación de otros autores; citemos por ejemplo el rol de los sectores populares en las democratizaciones vividas en África y la participación de grupos religiosos (Bratton y Van de Walle, 1997) (Coulon y Constantin, 1997).

A pesar de la cantidad considerable de textos que abordan la cuestión de las transiciones a la democracia, el interés sobre la relación entre la historia y los cambios de régimen no ha sido estudiado con detalle. Tal y como es señalado por Guy Hermet, los autores ligados principalmente al estudio estratégico de las transiciones no se han necesariamente distinguido por su interés hacia el pasado (Hermet, 2001). Dentro de los pocos documentos que abordan dicho tema, es posible distinguir dos distintas maneras de evocar la historia dentro del análisis de las transiciones. La primera de ellas subraya la importancia del pasado desde la perspectiva de las instituciones políticas. En otros términos, presta atención a la influencia de la herencia institucional del antiguo régimen sobre las nuevas instituciones. Sobre este punto, Karl y Schmitter señalan que incluso si fueran creadas nuevas instituciones en el nuevo sistema democrático, estas pueden verse afectadas por la forma en que funcionaban las anteriores (Karl y Schmitter, 1991). La segunda es utilizada principalmente en el estudio de las transiciones llevadas a cabo después de una guerra civil o tras un régimen con una alta represión política. En este caso es común abordar temas como la reconciliación nacional y la impartición de justicia, agrupados bajo el nombre de "justicia transicional", por medio de diversas acciones tales como la promulgación de una amnistía general, los procesos públicos, la creación de comisiones de la verdad, las compensaciones de orden económico y ciertos gestos simbólicos (Rigby, 2001).

A pesar de estos contados esfuerzos por tomar en cuenta la variable histórica dentro del estudio de las transiciones a la democracia, uno de los aspectos que continúa dejándose de lado es la manera en la cual los ciudadanos tienen que tornar la vista al pasado, olvidando las manipulaciones históricas del autoritarismo $y$ teniendo acceso a otras interpretaciones sobre distintos eventos ocurridos años, décadas o siglos atrás. Una de las ventanas que permiten contemplar justamente una nueva versión de los hechos históricos es la pantalla cinematográfica.

\section{EL CINE Y LA TRANSITOLOGÍA}

Tal y como señalamos anteriormente, las relaciones entre la ciencia política y el cine 
nunca han sido verdaderamente cercanas. El cine como objeto de estudio no ha logrado despertar un interés importante en los politólogos, a pesar de tratarse de un espacio capaz de difundir ideas, valores, conductas y reflexiones de orden político provenientes de todo tipo de ideologías y con una enorme capacidad de difusión entre la ciudadanía. Para Manuel Trenzado Romero, dicho desinterés puede explicarse principalmente por tres factores: el peso predominante del institucionalismo en la ciencia política, la falsa convicción de que la ficción está alejada de toda realidad política y la apropiación del estudio del séptimo arte por parte de otras disciplinas (Trenzado, 2000: 47). Las pocas alusiones al celuloide dentro de la ciencia política las podemos encontrar por ejemplo, en algunos estudios sobre el cine de propaganda propio de los totalitarismos y sobre el desarrollo del Tercer Cine, de inspiración marxista, en los países periféricos.

Pese a no citar directamente el papel del séptimo arte dentro de las dinámicas propias de la transición, algunos estudiosos subrayan la importancia de los artistas dentro de la lucha por transitar de un régimen autoritario a uno de corte democrático. O'Donnell y Schmitter mencionan el valor de los creadores artísticos para formar un bloque opositor al autoritarismo y para promocionar una alternativa democrática (O’Donnell y Schmitter, 1986: 49), mientras que Guy Hermet identifica a ciertos artistas como actores importantes en la legitimación del nuevo sistema democrático (Hermet, 1993: 215-216).

Recorriendo la literatura sobre los cambios de régimen, podemos constatar que los estudios que llegan a tomar en cuenta el papel del cine son casi inexistentes. Dentro de las pocas excepciones, podemos citar el texto de Peter Hopkinson, centrado en una perspectiva desarrollista, respecto a la cámara como instrumento de difusión de los avances tecnológicos al mismo tiempo que como herramienta de unidad nacional (Hopkinson, 1972). Cultura de masas y cambio político: el cine español de la transición de Manuel Trenzado Romero se ha consolidado como la obra pionera en la materia. En este documento el autor analiza, desde la perspectiva de la cultura de masas, de qué forma los cambios políticos afectaron al cine como institución social a su vez que dentro de sus contenidos fílmicos (Trenzado, 1999). Invirtiendo las variables, otros textos han querido explicar el papel del cine dentro de la transición española al centrar su atención en la capacidad del séptimo arte en difundir nuevos valores y en elaborar críticas del ancien régime (Porras, 2008). Continuando con esta misma línea de análisis, es decir, tomando en cuenta la capacidad del cine para difundir mensajes de protesta $y$ de promoción de ciertas actitudes ${ }^{1}$, es posible constatar que la cámara cinematográfica puede ser empleada para proyectar justamente uno de los temas más polémicos durante un cambio de régimen. Nos referimos específicamente a la discusión de cuestiones históricas. En efecto, distintos tópicos ligados al pasado, frecuentemente ignorados por parte de los actores políticos encargados de negociar y acordar los cambios institucionales que propicien la transición, pueden tener cabida en las salas cinematográficas, aprovechando el enorme potencial de difusión de películas $y$ documentales. Más allá del deseo por parte de las élites políticas de abordar toda cuestión histórica o bien de suprimirla completamente dentro de las dinámicas propias de una transición política, el cine puede convertirse en un espacio donde los ciudadanos pueden discutir sobre el pasado. Sobre este punto específico, y tal y como lo afirma Jean-François Bayart, las expresiones culturales son de gran utilidad a fin de ejercer un contrapeso sobre la hegemonía discursiva de las élites (Bayart, 1981: 57). Dentro de dichas expresiones culturales, el cine puede jugar un papel importante al representar

1 Hablamos en este caso del uso del séptimo arte como espacio de difusión de ideas prodemocráticas. Es necesario, sin embargo, señalar que los cineastas no siempre defienden las mismas ideologías políticas. Tal y como se puede constatar en cualquier disciplina artística, en el cine se encuentran representadas las más variopintas concepciones sobre el mundo; pensemos por ejemplo en realizadores anarquistas, de aspiración marxista, fascistas, otros más cercanos a la democracia liberal o bien, algunos definitivamente apolíticos. 
un foro para las discusiones históricas y de esta manera convertirse en una poderosa ventana al pasado.

A lo largo de varias décadas, distintos autores han subrayado la capacidad del cine para ser empleado como herramienta de la enseñanza de la historia (Ferro, 1984). Incluso algunos historiadores comentan que el lenguaje cinematográfico tiene muchas veces un impacto mayor para la difusión histórica que la propia palabra escrita (Raack, 1983: 416-418). Las películas se convierten de esta forma en medios de producción de discursos históricos y los directores constatan que por medio del lenguaje cinematográfico es posible reconstruir y restituir la memoria colectiva (Amador, 1996: 114-115). A través de la imagen fílmica, los ciudadanos pueden presentar visiones alternativas sobre determinados eventos históricos, yendo a contracorriente de la historia oficial, característica de los regímenes autoritarios y generalmente instrumento de manipulación hacia la ciudadanía. De esta manera, y tal y como es señalado por diversos autores, el cine, además de ser sinónimo de entretenimiento y disciplina artística, se convierte también en un espacio para transmitir valores $y$ mensajes ligados a la vida de otras personas, transformándose entonces en una experiencia vicaria (García Amilburu, 2002).

Eventos como la guerra civil, el exilio, las precarias condiciones de vida durante el franquismo y los perseguidos políticos de las distintas comunidades regionales han estado ligados a la amnesia, al debate $y$ a la polémica para los españoles desde el comienzo mismo de la transición. De igual manera, la represión gubernamental dirigida hacia los jóvenes en 1968 y el nacimiento, el desarrollo y la forma de operar del otrora partido de Estado han sido también delicados temas para autoridades y ciudadanos de México en las últimas dos décadas. Frente a la complejidad de abordar dichas cuestiones a través de los canales institucionales, algunos cineastas de estos dos países expresaron sus ideas al respecto en sus creaciones fílmicas, proponiendo nuevas formas de interpretar el pasado en periodos específicos de transformación político-institucional.

\section{EL PASADO Y EL CINE ESPAÑOL DE LA TRANSICIÓN}

A pesar del consenso en los círculos académicos sobre el éxito de la transición en España, algunos estudiosos hablan del grave error que significó para los políticos el haber suprimido cualquier alusión a la historia durante dicho periodo de cambio. Como ejemplo, Josep María Colomer comenta que esta amnesia respecto al pasado hizo que las virtudes de la transición devinieran los vicios de la democracia (1998: 10, 181). En efecto, las alusiones al pasado fueron evitadas sistemáticamente por parte de las élites encargadas de negociar el cambio de régimen, bajo la firme idea de no poner en peligro los acuerdos y compromisos entre las partes. Dicho silencio fue conocido bajo el nombre de "pacto del olvido" (Rigby, 2001: 12-13).

Paradójicamente, uno de los pilares ideológicos del franquismo fue durante muchos años el uso del discurso histórico como elemento de legitimación. Para las autoridades franquistas, sólo la versión oficial de la historia tenía cabida en la sociedad española. Dicha versión estaba sustentada en la imagen de Franco como salvador de los valores y los intereses de la patria, en la división flagrante entre vencedores $y$ vencidos $y$ en la nula posibilidad de que estos últimos pudieran tener voz. Esta estrategia ideológica fue conocida bajo el nombre de "pacto de sangre" (Rigby, 2001: 44).

En el caso específico de la transición española, es importante señalar que el cine fue uno de los pocos terrenos - pese a diversas polémicas y a algunos desatinos-donde fue posible observar una serie de ideas sobre el pasado distintas al discurso oficial omnipresente durante varias décadas. Así, Paloma Aguilar comenta que diversos espacios tales como las investigaciones académicas, las obras literarias $y$ en especial, el cine, abordaron el pasado a pesar del silencio generalizado sobre dicho tema (Aguilar, 2004: 25). Efectuando un recorrido sobre las producciones fílmicas durante la transición española, podemos darnos cuenta que la evocación del pasado fue un tema común en la pantalla grande. Se habla incluso del desarrollo de un género cinematográfico particular 
en aquel periodo conocido como "cine de recuperación de la memoria colectiva" (Molina Foix, entrevista, 2005).

Desde una perspectiva política, el análisis de algunas de las cintas más representativas del cine español de la transición resalta la importancia que tuvo para algunos directores el hecho de hacer alusión a los eventos históricos, un tema prohibido durante varias décadas y cuya única fuente provenía del aparato propagandístico franquista. De esta manera, se trataba de brindar al público una lectura del pasado a contracorriente de la historia oficial. Esta forma de proceder por parte de algunos miembros de la comunidad cinematográfica va en la misma dirección de lo que comenta Guy Hermet, respecto a la responsabilidad por parte de los creadores artísticos para contribuir a la desmitificación de los discursos heredados del antiguo régimen (Hermet, 1993: 214). Las películas históricas realizadas durante los años de la transición se ocuparon de recrear diversas épocas de la historia de España. Creemos sin embargo, que por su importancia política, dos momentos históricos fueron abordados con mayor frecuencia. Nos referimos específicamente a la guerra civil (1936-1939) y al periodo inmediato que le sucedió, es decir aquel que abarca la postguerra y los primeros años del franquismo (1939-1953)2.

Durante los años de vida del régimen franquista, únicamente tenía cabida una sola explicación a propósito de la guerra civil. Así, esta era descrita como una verdadera "cruzada" en contra de los enemigos de la nación. Dicho discurso también llegó al mundo cinematográfico, uno de los instrumentos preferidos por las autoridades franquistas para desarrollar toda una mitología respecto al conflicto armado. Hablamos por ejemplo de películas como Raza (1941), cinta de Gonzalo Herralde basada en un argumento escrito por el propio Francisco Franco bajo el seudónimo de Jaime de Andrade,

Esta fecha abarca del término de la guerra civil a la firma del pacto militar entre el régimen franquista y los Estados Unidos de América. Dicho pacto ayudó a terminar con el distanciamiento de España con una buena parte de la comunidad internacional. y Franco: ese hombre (1964) de José Luis Sáenz de Heredia. En los años de la transición, algunos directores españoles optaron por abordar este espinoso tema desde otra perspectiva. Luego de décadas bajo el discurso oficial, el cual abordaba la guerra con tintes heroicos $y$ marcaba una profunda división entre vencedores $y$ vencidos, varios miembros del mundo cinematográfico optaron por hacer pública una nueva visión del conflicto bélico. Se trataba a ciencia cierta de recuperar una idea desarrollada por algunos miembros de la vida artística española durante la guerra $y$ al final de la misma. Hablamos específicamente del término "cainismo", es decir, del hecho de considerar la guerra civil como una tragedia colectiva, como un duelo entre hermanos de la misma nación, de nefastas consecuencias para todos (Deveny, 1993). En efecto, entre 1973 y 1977, fueron producidas en España algunas películas que no dudaban en señalar el carácter trágico y sangriento de la guerra civil, enseñando en la pantalla el drama producto del conflicto $y$ por primera vez en muchos años, otorgando una voz a los sectores republicanos. Entre todas ellas, podemos citar por su importancia en primer lugar a Pascual Duarte (1976) de Ricardo Franco. Basada en la novela de Camilo José Cela, la cinta de Franco está ambientada en los años que preceden al comienzo del conflicto. En esta película, se evidencian las tensiones y las difíciles condiciones de la España de la época. Virginia Higginbotham comenta que se trata hasta cierto punto de un documento etnográfico cuya intención es de mostrar la intolerancia y la corrupción de las estructuras sociales del medio rural (1988: 109). Incluso, Carmen de Elejabeitia y F. de Castro van más lejos en sus comentarios afirmando que la película sirve para desenmascarar las verdaderas causas de la guerra civil: el problema de la propiedad de la tierra y las tensiones producto de las malas relaciones entre las distintas clases sociales (1977: 13). Dos obras fílmicas que describen con detalle el caos y la desolación de los años de la guerra son tanto Retrato de familia (1976) de Antonio Jiménez Rico como Las largas vacaciones del 36 (1976) de Jaime Camino. En estas dos cintas, queda de manifiesto el drama provocado 
por la guerra dentro de las familias españolas. En Retrato de familia, la primera película donde se aborda la guerra civil después de la muerte de Franco, se muestra el dolor de una familia simpatizante con la causa nacionalista al perder a su único hijo en el frente de batalla. En Las largas vacaciones del 36, Jaime Camino — de la mano de Manuel Gutiérrez Aragón, guionista de la cinta-muestra por una parte las difíciles condiciones a las que se tuvieron que enfrentar miles de familias españolas, aun lejos del sonido de las balas; por la otra, el director aspira a presentar un rostro más acorde con la realidad de muchos de los seguidores de la causa republicana en Cataluña: individuos en su mayoría herederos de una tradición liberal, con una identidad nacional distinta, lejos del fanatismo comunista estereotipado durante muchos años por el régimen (Gutiérrez Aragón, entrevista, 2005). Cabe señalar que en dicha película aparece por primera vez la bandera republicana, luego de cerca de cuarenta años de considerársele un símbolo prohibido (Monterde, entrevista, 2005). A través de estas y otras cintas, se trataba entonces de romper con la interpretación oficial de la guerra civil impuesta por el régimen durante tanto tiempo, desmitificando el conflicto y abordándolo como lo que fue: una tragedia colectiva que continuaba pesando en las conciencias de los españoles.

El segundo gran tema histórico abordado por algunos directores de la transición se sitúa en los años de la postguerra y de consolidación del régimen franquista. En efecto, por medio de la cámara, diversos cineastas decidieron presentar públicamente la imagen de una España hundida en la miseria, sujeta a una represión incesante $y$ donde diversas actividades ilícitas, como el tráfico y el estraperlo, eran actividad cotidiana. En una línea muy próxima al cine metafórico, Víctor Erice aborda en El espíritu de la colmena (1973) el difícil ambiente de la postguerra. Considerada como una de las obras maestras del cine español, la cinta de Erice describe en un estilo más críptico y altamente poético, la vida de una familia simpatizante de la causa republicana en los campos de Castilla a principios de los años cuarenta. A pesar de no tratarse de una simple película de recreación histórica, podemos constatar en ella diversos pasajes que sirven para dar cuenta del clima de desolación de aquella época. De acuerdo con Jaime Pena, la película consigue ilustrar a la perfección el sentimiento de tristeza $y$ de desesperanza, hablando de una verdadera "estética de la derrota" (2004: 56). En El espíritu de la colmena, el silencio deviene como elemento fundamental. En la propia opinión de Erice, dicho silencio es un recuerdo constante de su infancia, de aquel mutismo introspectivo de una población traumatizada por la tragedia colectiva (Morgan, 1993: 27). De igual manera, la cinta sirve para retratar la condición de muchos españoles que, a causa de sus ideas políticas, tuvieron que vivir el exilio interior, condenados a callar y a pasar inadvertidos. Otra película que aborda las condiciones de vida de la postguerra es Pim, Pam, Pum ..., iFuego! (1975) de Pedro Olea. A través de la historia de Paca, una bailarina de cabaret enamorada de un miembro de los maquis y chantajeada por un estraperlista, Olea consigue recrear con éxito el Madrid de los años cuarenta, entre el racionamiento y los traumas de la guerra. En este sentido Pim, Pam, Pum..., ;Fuego! subraya la importancia de los alimentos durante ese periodo histórico. Además de señalar los problemas alimentarios de la postguerra, Olea efectúa en su película una crítica directa a la corrupción generalizada $y$ a las fortunas amasadas ilegalmente en esa época. El propio director comenta que al momento de su estreno, el film provocó la cólera de algunos sectores ligados al franquismo, quienes se sintieron señalados directamente en la pantalla (Olea, entrevista, 2005). De esta manera, Pim, Pam, Pum ..., iFuego! representó un esfuerzo más para abordar diversos aspectos del pasado español silenciados durante varias décadas.

\section{EL CINE MEXICANO, LA DERROTA DEL PARTIDO REVOLUCIONARIO INSTITUCIONAL (PRI) Y LA HISTORIA OFICIAL}

A diferencia del caso español, señalado por muchos como ejemplar y que incluso derivó en el desarrollo de modelos explicativos basados en las decisiones estratégicas de las 
élites políticas, la transición mexicana continúa representando un desafío para los politólogos $y$ lejos de provocar un consenso en sus etapas $y$ dinámicas, incita hasta la fecha opiniones encontradas y divergentes. Desde la década de los noventa, algunos autores dejaban ya entrever la transformación del sistema político mexicano, anunciando un cambio irreversible en las formas de ejercer el poder en el país (Cornelius, 1996) (Morris, 1995).

A pesar de que la democracia mexicana no siguió necesariamente los mismos pasos que el caso español, por tratarse de situaciones con contextos distintos, un cambio generacional de nuevos políticos priístas permitió imaginar un viraje hacia una vida política más democrática (Centeno, 1997). Contrariamente a esta idea, Mauricio Merino comenta que México experimentó una transición "votada" y no "pactada", donde no existió necesariamente una verdadera ruptura, en un escenario en el cual se recuperaron instituciones políticas sin tener que diseñar necesariamente otras nuevas (Merino, 2003). De esta manera, las elecciones presidenciales del 2000 ganadas por el candidato del opositor Partido Acción Nacional (PAN), Vicente Fox Quesada, permitieron que el país circulara a un escenario democrático pero sin romper con los actores políticos tradicionales.

Uno de los pilares fundamentales del antiguo régimen priísta fue su férreo control sobre todas las esferas sociales del país. En efecto, el régimen del PRI manejaba la distribución de recursos, el manejo de la información $y$ el ejercicio del poder en cualquier escenario posible. Por ende, resultaba imposible expresar ideas que chocaran de frente con los intereses del partido de Estado. Ejemplo de todo ello fue el uso de la historia oficial como instrumento de legitimación política, donde se hacía alusión a mitos nacionales $y$ a verdades a medias justamente para tratar de persuadir a la ciudadanía de la supuesta fuerza histórica del régimen y de la justificación de muchas de sus acciones (Crespo, 2009). De esta manera, distintos pasajes de la historia mexicana eran interpretados $y$ adaptados a conveniencia del régimen. Además de concentrar la atención en algunos personajes $y$ en diversos eventos del pasado, los encargados de diseñar la historia oficial también decidían los acontecimientos que debían ser olvidados, tales como los ejemplos de la represión política $y$ las acciones llevadas a cabo por los opositores.

En un régimen caracterizado por el castigo, las prebendas y las decisiones patrimonialistas, no es difícil imaginar una esfera cinematográfica afectada también por esta forma de hacer política. En efecto, el cine mexicano representante de estas décadas de autoritarismo se distinguió por el uso sistemático de la censura y el financiamiento sólo a aquellos productos que no pusieran en entredicho la línea oficial, $y$ donde los intentos de crítica a través de la cámara no fueron verdaderamente numerosos (Mora, 1989) (Monsiváis y Bonfil, 1994), a pesar del esfuerzo de algunos directores por tratar de retratar varios de los problemas sociales. Sobre esta visión oficialista, hablamos por ejemplo de películas enfocadas en subrayar las costumbres propias de las "buenas familias" mexicanas - basta recorrer varios de los éxitos del melodrama de los años cuarenta y cincuenta-y de la descripción de la lucha revolucionaria como tema glorioso y alejado de cualquier crítica - pensemos en algunas obras de Emilio Fernández y Fernando de Fuentes-.

A medida que el país experimentaba cambios en el escenario político, fue sintiéndose una mayor distensión en los mecanismos propios de la censura, permitiendo difundir poco a poco algunos mensajes políticos dentro del séptimo arte. De esta manera, algunos cineastas decidieron abordar en sus obras temas que tenían que ver directamente con varias de las páginas de la historia nacional, llevando a la pantalla eventos tan específicos como la represión hacia los estudiantes en 1968 y en la denominada "Matanza del Jueves de Corpus" de 1971, el fraude electoral de 1988, las históricas formas de ejercer el poder por parte de los políticos priístas y la actuación política en el pasado de sectores como la Iglesia y la iniciativa privada.

Uno de los episodios más polémicos en la historia mexicana de los últimos cincuenta años fue la represión por parte del régimen hacia varios sectores disidentes, en especial hacia los jóvenes universitarios, a finales de la década de los sesenta $y$ a principios de los setenta. Durante 
años, el aparato oficial se dedicó a borrar de golpe toda alusión a dicho evento o a comentarlo escuetamente como una conspiración internacional en contra de las instituciones políticas del país. De esta manera, tanto la matanza del 2 de octubre de 1968 como el ataque a los estudiantes el 10 de junio de 1971 circularon mucho tiempo como rumores en los escenarios privados, sin explicación oficial por parte de las autoridades. Con la llegada de Miguel de la Madrid y de Carlos Salinas de Gortari al poder respectivamente, se pudieron constatar algunas acciones que, por una parte, hablaban de una liberalización en lo económico y en la participación de la derecha en algunas regiones del país $y$, por la otra, cerraban el cerco ante los opositores de la izquierda por medio de asesinatos $y$ secuestros. Dentro de este paradójico clima de ciertas "libertades" y de constantes acechos, una película iba a provocar distintas polémicas dentro de la sociedad mexicana. Rojo amanecer (1989) de Jorge Fons trata de la matanza perpetrada en 1968 contra los estudiantes en la Plaza de las Tres Culturas de Tlatelolco, convirtiéndose en la primera cinta en abordar directamente uno de los tabúes de la historia nacional. Después de año y medio de espera, Rojo amanecer fue autorizada y exhibida en todo el país con gran éxito (Aviña, 2004: 42). Dentro de todos los sectores del régimen, fueron los militares quienes ejercieron una mayor presión para evitar que la película fuera proyectada públicamente, al aparecer en varias escenas como participantes directos de la represión. Finalmente, levantaron el veto a la cinta a cambio de que el director suprimiera varias tomas donde figuraban miembros de las fuerzas castrenses (Velazco, 2005: 72). Teniendo como protagonistas a los miembros de una familia de clase media residente en uno de los edificios de Tlatelolco, Fons presenta una versión de la masacre ligada a cientos de testimonios y que denuncia la participación directa de diversas instituciones oficiales. De acuerdo con el crítico cinematográfico Leonardo García Tsao, el objetivo de la cinta era perturbar y recuperar la indignación ante un crimen gubernamental, además de significar la primera representación en el cine de ficción de un hecho que ha marcado a generaciones enteras (2008:
75). Filmada con pocos recursos económicos, Rojo amanecer consigue recrear el clima de incertidumbre, temor y zozobra de una típica familia mexicana, con diferencias generacionales e ideológicas entre sus miembros y víctima de la violencia de Estado.

En este mismo esfuerzo por citar públicamente eventos dolorosos de la historia mexicana, Gabriel Retes filma en 1991 El bulto, obra que aborda la represión del régimen en la denominada "Matanza del Jueves de Corpus", evento ocurrido el 10 de junio de 1971 donde fuerzas paramilitares $y$ policías golpearon $y$ asesinaron a decenas de estudiantes que se manifestaban pacíficamente. En la película, Lauro, un fotógrafo de la prensa, es golpeado por un policía, lo cual le produce entrar en estado de coma durante veinte años. Al despertar, se encuentra con un país cambiado, donde el PRI sigue reinando y sus antiguos camaradas han perdido los ideales. Filmada en pleno sexenio de Carlos Salinas de Gortari, El bulto exhibe por primera vez en la pantalla grande aquel evento tabú sobre la represión gubernamental, además de mostrar un conflicto generacional entre un padre aferrado a sus ideas, un hijo producto de otra generación y un contexto social distinto al de los años setenta (González Vargas, 2006: 68-69), pero que aún no da paso a un país de plenas libertades.

Durante los años de la transición mexicana, una de las películas que provocaron mayor interés por parte de la ciudadanía, el mundo intelectual y las autoridades gubernamentales fue La ley de Herodes (1999) del cineasta Luis Estrada. En ella son retratados hábitos y protagonistas de la política priísta que controló al país durante siete décadas. En efecto, sirviéndose de varios elementos de la comedia, Estrada aborda en la pantalla grande las formas de actuar en lo político del México de los años cuarenta $-y$ de buena parte del siglo Xx- La cinta cuenta la historia de Juan Vargas, un joven burócrata enviado a gobernar un poblado del México profundo y que tiene que vivir todo un proceso de educación política que le permita ejercer el poder en la manera "clásica" de los años del PRI. En La ley de Herodes no sólo estamos frente a una negra sátira sobre el partido político que 
gobernó durante décadas sino también ante una película que aborda la forma de actuar en lo político de otras instituciones tales como la Iglesia, la oposición de derecha y la iniciativa privada (Tovar, 2000: 49) (González Vargas, 2006: 168). Estos actores se ven involucrados en uno de los temas fundamentales de la cinta de Estrada: la corrupción sistemática en todos los niveles. Debido a las temáticas abordadas en ella, la película sufrió algunos intentos de censura por parte de las autoridades, los cuales en vez de provocar desinterés por parte de la ciudadanía devinieron una publicidad efectiva para la obra de Luis Estrada, perdiendo el régimen una buena oportunidad para distanciarse de las viejas formas de suprimir mensajes políticos en el cine (García Tsao, 2008: 115).

Otro evento histórico no exento de la polémica y presente en el cine es el fraude electoral en las elecciones presidenciales de 1988, donde el régimen tuvo que anunciar fallas en el sistema de conteo de votos para "maquillar" cifras y otorgar el triunfo a Carlos Salinas de Gortari, candidato del PRI. Dicho evento histórico aún presente en la memoria de los mexicanos ha sido también abordado en el cine. En efecto, Carlos Mendoza, cineasta egresado el Centro Universitario de Estudios Cinematográficos (CUEC) filma Crónica de un fraude (1988), donde a través de distintas imágenes narra la campaña de Cuauhtémoc Cárdenas, candidato opositor del Frente Democrático Nacional, el fraude electoral orquestado por el régimen y el anuncio oficial del triunfo de Carlos Salinas de Gortari (Aviña, 2004). Presentado públicamente en muy contadas ocasiones, Crónica de un fraude se convirtió en todo un fenómeno al ser la primera vez que la ciudadanía adquiría una cinta en video para informarse de un evento político, buscando una explicación alternativa a la versión oficial de la supuesta victoria electoral del PRI. En tiempos más recientes, Fraude: México 2006 (2007) del cineasta Luis Mandoki no ha estado exenta de la polémica al denunciar públicamente un fraude masivo en las elecciones presidenciales de 2006 en contra de Andrés Manuel López Obrador, candidato de la izquierda, y que benefició directamente a Felipe Calderón Hinojosa, candidato del Partido Acción Nacional.

\section{CONSIDERACIONES FINALES}

Los casos de España y México muestran la capacidad del cine en convertirse en un espacio efectivo para presentar a la ciudadanía nuevos discursos sobre la historia, diferentes de las explicaciones oficiales sobre el pasado. Durante la transición española, algunos cineastas comprendieron la necesidad de escapar a la historia difundida por el franquismo y exhibir en la pantalla temas vetados o tergiversados durante décadas. Tal fue el caso de la guerra civil - una lucha fraticida y no una cruzada contra los enemigos de la "España eterna"-, la postguerra - un periodo de grandes carencias $y$ de represión sistemática contra los perdedores de la guerra-y los años del franquismo - una página de la historia caracterizada por la violencia y el control férreo del régimen-. De esta manera, el cine español devino uno de los pocos espacios que, contrariamente a la actitud de las élites políticas, no ignoró hablar sobre los polémicos temas del pasado y su impacto en el presente.

En el caso mexicano, luego de siete décadas de un férreo control priísta donde una parte de la legitimidad del régimen recaía en la historia oficial, el séptimo arte se transformó en una ventana abierta a temas polémicos y reinterpretaciones sobre algunos eventos históricos. Hablamos específicamente de la represión hacia los estudiantes en 1968 y 1971, el fraude electoral y las formas cotidianas de operar en la esfera política por parte de los distintos actores políticos en los largos años del régimen. Como Salvador Velazco atina en subrayar, además de ir a contracorriente de la historia oficial, las películas mexicanas referidas en nuestra investigación sirvieron para aglutinar en torno suyo a la sociedad civil, a los medios de comunicación y a la comunidad cinematográfica en la defensa de la libertad de expresión (2005: 68).

El papel del cine en los procesos de transformación político-institucional en España y México nos permite constatar que, a diferencia de algunos autores que reducen las transiciones a simples cambios institucionales, es necesario que la población lleve a cabo un proceso de cambio de valores, donde poco a poco queden 
segregados aquellos heredados de los regímenes autoritarios, dando entrada a costumbres, comportamientos y actitudes más cercanos a la vida en democracia. Tal y como es comentado por el cineasta Manuel Gutiérrez Aragón respecto a la transición española, es fundamental que una sociedad se "normalice" después de años o décadas de cultura autoritaria (Gutiérrez Aragón, entrevista, 2005).

Además de querer insertar nuestro análisis en los terrenos del cambio de valores $y$ de las formas de estudio de las transiciones, uno de nuestros mayores propósitos ha sido el de subrayar la importancia del cine como objeto de interés para diversas disciplinas de las ciencias sociales. El celuloide, además de representar una expresión artística, un fenómeno de masas y una industria con sólido poder económico, puede también convertirse en un espacio de reflexión social a su vez que una herramienta de enseñanza sobre las relaciones entre los ciudadanos. Es por ello que existe la necesidad de ampliar las perspectivas de análisis sobre el cine en las ciencias sociales y de otorgarle la importancia que se merece dentro de la vida de nuestras sociedades.

\section{BIBLIOGRAFÍA}

Amador Carretero, Pilar. "El cine como documento social: una propuesta de análisis". Díaz Barrado, Mario (ed.). Imagen et Historia. Madrid. Marcial Pons, 1996: 113-145.

Aviña, Rafael. Una mirada insólita: temas y géneros del cine mexicano. México: Cineteca Nacional; Editorial Océano, 2004.

Badie, Bertrand. Le développement politique. París: Económica, 1988.

Bratton, Michael y Van de Walle, Nicolas. Democratic Experiments in Africa: Regime Transitions in Comparative Perspective. Cambridge: Cambridge University Press, 1997.
Centeno, Miguel A. Democracy Within Reason: Technocratic Revolution in Mexico. 2da. Edición. University Park, Pa: Pennsylvania State University Press, 1997.

Colomer, Josep María. La transición a la democracia: el modelo español. Barcelona: Anagrama, 1998.

Cornelius, Wayne A. Mexican Politics in Transition: The Breakdown of a OneParty-Dominant Regime. La Jolla, CA: Center for U.S.-Mexican Studies, University of California, San Diego, 1996.

Coulon, Christian y Constantin, François (dir.). Religion et transition démocratique en Afrique. París: Éditions Karthala, 1997.

Crespo, José Antonio. Contra la historia oficial. México: Debate, 2009.

De Elejabeitia, Carmen y De Castro, Ignacio F. "Prólogo". Franco, Ricardo, Lázaro, Emilio M., y Querejeta, Elías. Pascual Duarte. Madrid. Elías Querejeta Ediciones, 1977: 7-16.

Deveny, Thomas G. Cain on Screen. Contemporary Spanish Cinema. Lanham, MD: Scarecrow Press, 1993.

Ferro, Marc. Film et Histoire. Paris: Éditions de l'École des Hautes Études en Sciences Sociales, 1984.

García Tsao, Leonardo. El ojo y la navaja: ensayos y críticas de cine. 2 da Edición. México: Punto de lectura, 2008.

Gazibo, Mamoudou y Jenson, Jane. La politique comparée. Montreal: Presses de l'Université de Montréal, 2004.

González Vargas, Carla. Rutas del cine mexicano 1990-2006. México: Conaculta; 
Instituto Mexicano de Cinematografía, 2006.

Hermet, Guy. Culture et Démocratie. Paris: Albin Michel, UnESCO, 1993.

Higginbotham, Virginia. Spanish Film under Franco. Austin: University of Texas Press, 1988.

Hopkinson, Peter. The Role of Film in Development. Paris: UNESCO, 1972.

Huntington, Samuel. The Third Wave: Democratization in the Late Twentieth Century. Norman: University of Oklahoma Press, 1991.

Linz, Juan y Stepan, Alfred. Problems of Democratic Transition and Consolidation: Southern Europe, South America, and Post-communist Europe. Baltimore, MD: Johns Hopkins University Press, 1996.

Merino, Mauricio. La transición votada: crítica a la interpretación del cambio politico en México. México: Fondo de Cultura Económica, 2003.

Monsiváis, Carlos y Bonfil, Carlos. A través del espejo: el cine mexicano y su público. México: Ediciones El Milagro; Instituto Mexicano de Cinematografía, 1994.

Mora, Carl. J. Mexican Cinema: Reflections of a Society 1896-1989. 2da. Edición. Berkeley: University of California Press, 1989.

Morris, Stephen, D. Political Reformism in Mexico: an Overview of Contemporary Mexican Politics. Boulder: L. Rienner, 1995.

O’Donnell Guillermo. "Transitions, Continuities, and Paradoxes". Mainwaring, Scott,
O'Donnell, Guillermo y Valenzuela, Samuel. Issues in Democratic Consolidation. Notre Dame. University of Notre Dame Press, 1992: 17-56.

O’Donnell, Guillermo y Schmitter, Philippe. Transitions from Authoritarian Rule. Tentative Conclusions About Uncertain Democracies. Baltimore: Johns Hopkins University Press, 1986.

Pena, Jaime. El espíritu de la colmena. Estudio crítico. Barcelona: Ediciones Paidós, 2004.

Rigby, Andrew. Justice and Reconciliation. Boulder \& London: Lynne Rienner Publishers, 2001.

Trenzado Romero, Manuel. Cultura de masas y cambio político: el cine español de la transición. Madrid: Centro de Investigaciones Sociológicas. Siglo XXI, 1999.

\section{HEMEROGRAFÍA}

Aguilar, Paloma. "Guerra civil, franquismo y democracia”. Claves de razón práctica 140, marzo. 2004: 24-33.

Bayart, Jean-François. "Le politique par le bas en Afrique noire". Politique africaine 1 (1), enero. 1981: 53-82.

Carothers, Thomas. "The End of the Transition Paradigm”. Journal of Democracy 13 (1). 2002: 5-21.

García Amilburu, María. "Historias de hombres y mujeres en términos de luz: el papel del cine en la educación". Revista Mexicana de Investigación Educativa 7 (15). 2002: 357-369.

Hermet, Guy. "Les démocratisations au vingtième siècle: une comparaison 
Amérique latine/Europe de l'est". Revue Internationale de Politique Comparée 8 (2). 2001: 285-304.

Karl, Terry Lynn y Schmitter, Philippe. "Les modes de transition en Amérique latine, en Europe du Sud et de l'Est". Revue Internationale de Sciences Sociales 128, mayo. 1991: 285-301.

Morgan, Rikki. "Victor Erice: Painting the Sun". Sight and Sound 3 (4). 1993: 26-29.

Raack, R. J. "Historiography as Cinematography: A Prolegomenon to Film Work for Historians". Journal of Contemporary History 18, julio. 1983: 416-418.

Tovar, Luis. "La ley de Herodes: más real que la realidad". Cinemanía 41, febrero. 2000: 48-49.

Trenzado Romero, Manuel. "El cine desde la perspectiva de la ciencia política". Revista española de investigaciones sociológicas 92, octubre-diciembre. 2000: 45-70.

Valenzuela, Arturo. "Latin America: Presidentialism in Crisis". Journal of Democracy 4 (4), octubre de 1993: 3-16.
Velazco, Salvador. "Rojo amanecer y La ley de Herodes: cine político de la transición mexicana". Hispanic Research Journal 6 (1), febrero. 2005: 67-80.

\section{PÁGINAS ELECTRÓNICAS}

Porras Ferreyra, Jaime. "El cine y las transiciones a la democracia: algunas reflexiones en base al caso español". CineHistoria XVIII (2). Centre d'Investigacions Film-Història, Universitat de Barcelona, 2008. En: <http://www.pcb.ub.es/ filmhistoria/ensayo_cine_transicion_1. html>

\section{ENTREVISTAS}

Gutiérrez Aragón, Manuel. Cineasta y guionista español. Madrid, 19 de octubre de 2005.

Molina Foix, Vicente. Cineasta y escritor español. Montreal, 30 de agosto de 2005

Monterde, José Enrique. Profesor del Departamento de Historia del Arte de la Universidad de Barcelona. Barcelona, 20 de octubre de 2005.

Olea, Pedro. Cineasta español. Madrid, 28 de noviembre de 2005. 
